\title{
Comparison of short term outcomes of open and laparoscopic cholecystectomy
}

\author{
R Cleary, C W Venables, J Watson, J Goodfellow, P D Wright
}

\begin{abstract}
Objective-To compare the three month outcome of open and laparoscopic cholecystectomy.

Design-Prospective assessment of outcome for a series of patients encompassing the introduction of the laparoscopic technique.

Setting-One teaching hospital.

Patients-269 patients admitted for open cholecystectomy between January 1989 and March 1992 and 122 admitted for laparoscopic cholecystectomy between January 1991 and March 1992.
\end{abstract}

Main measures-Patients' reported symptoms and self assessed scores with the Nottingham health profile before operation and at three month follow up. Incidence of complications and adverse events after discharge.

Results-Similar improvements in symptom rates and health scores were seen regardless of surgical technique. A lower rate of postoperative complications was seen in the patients given laparoscopic surgery $(6 / 95(6 \%) v 45 / 235(19 \%))$, and their mean length of stay was lower (4.5 $v 9.8$ days). Similar results were obtained when the analysis was restricted to a subset of fairly uncomplicated cases (patients aged 60 or less without other illnesses on admission who were not undergoing emergency or urgent surgery), which constituted a larger proportion of the group given laparoscopy $(35 / 95(37 \%) v 40 / 235(17 \%))$. Between these two groups no significant difference was seen in the frequency of relevant readmissions to hospital or visits to general practitioners or accident and emergency departments.

Conclusion-Ideally, a new surgical technique would be evaluated in a randomised trial. In the absence of such a trial, this observational study provides some evidence that the switch from open to laparoscopic cholecystectomy has brought benefits, particularly in terms of reduced length of stay in hospital. A range of clinical and patient derived indicators suggests that these gains have not been associated with a reduction in the quality of the outcome at three months.

(Quality in Health Care 1995;4:13-17)

Keywords: short term outcomes, open cholecystectomy, laparoscopic cholecystectomy.

Introduction

Since its introduction at the end of the 1980s laparoscopic cholecystectomy has rapidly emerged as a popular alternative to the traditional open procedure in managing symptomatic gall stones. ${ }^{12}$ It is a keyhole technique, in which the gall bladder is removed by instruments that are inserted through several small incisions and guided by means of a laparoscope. In contrast, open cholecystectomy is a major abdominal operation requiring a substantial incision and is therefore likely to cause significant postoperative pain and require a longer period of recovery.

Wolfe et al noted that early reports of clinical experience with the new technique attributed to it advantages of diminished postoperative pain, shorter lengths of stay in hospital, and more rapid recovery to full activity. ${ }^{3}$ They also suggested that, in the United States at least, the uptake of the technique by surgeons was so swift that patients' demand for the new procedure was sufficient to preclude randomised comparisons with the open operation. Zucker et al, reporting on a series of 100 patients undergoing the laparoscopic procedure, estimated that an average of three or four bed days was saved per patient, and they found no evidence of increased incidence of complications after discharge ${ }^{4}$ However, they also suggested that certain technical complications, such as injury to the common bile duct, might have a higher incidence than in the open operation. They concluded that the raised rate reflected the learning curve associated with a new procedure.

As part of the larger CASPE/Freeman outcomes study, ${ }^{5}$ we have prospectively assessed since 1989 the short term outcomes in patients undergoing cholecystectomy at a teaching hospital in northern England. This period has encompassed a switch at the hospital from the open to the laparoscopic technique. In January 1989 all cholecystectomies were of the open type. By January 1992 the laparoscopic procedure accounted for $90 \%$ of the operations performed. Our continuing data collection during this transition allowed us to compare the results of the new procedure with the accumulated database of outcomes achieved with open cholecystectomy. The observational nature of this design, however, does not allow for randomisation between the two surgical techniques. This deficiency can, of course, result in an allocation bias: the outcomes of the two techniques might refect not only their relative effectiveness but also the differing characteristics of the two groups of patients. Indeed, in this study we thought that the patients selected for laparoscopy surgery during its introduction would be more likely to have fewer surgical risk factors than would the full range of patients undergoing cholecystectomy. 
Laparoscopic cholecystectomy has not been subjected to a randomised controlled comparison with the traditional open procedure. In the absence of such trials, and given the extent to which the technique is now established, observational studies seem to be the only way to assess relative effectiveness. We report an observational study designed to compare the three month outcomes of open and laparoscopic cholecystectomy. We tried to control for the allocation bias that is apparent from our data, having recognised that the potential for undetected bias means that conclusions should be drawn from the results with caution

The principles and experience behind the selected outcome indicators have been discussed in detail elsewhere ${ }^{6}$; however, it is useful to outline the rationale. Across the range of conditions and procedures studied within the wider programme, indicators were categorised as major adverse events, such as death or readmission; treatment complications, such as wound infection; technical success, a failed laparoscopic case being one in which the open procedure was opted for during the operation; relief of specific symptoms, such as pain; and general, self perceived, health status. The Nottingham health profile (NHP) was selected as the health status measure as it is a well established, generic (as opposed to disease specific) tool which could be expected to be practical to administer and sensitive to changes in the health of the target population. These expectations were confirmed in our earlier assessment of the validity of the profile as a measure of outcomes of cholecystectomy. The profile provides a relatively direct reflection of the patients' health and is balanced by the value of the clinically derived and condition specific measures, which may be more readily linked to clinical practice.

\section{Methods}

The data collection methods used in this study have been described in detail previously. ${ }^{8}$ All patients admitted for cholecystectomy between January 1989 and March 1992 were asked by a nurse to complete a preoperative assessment of their symptoms and Nottingham health profile questionnaire. The symptom assessment consisted of a series of yes/no questions covering pain, vomiting, tolerance of fatty foods, loss of appetite, flatulence, and abdominal distension. The questionnaire also included either a general question about bowel problems or two more specific items about constipation and diarrhoea. As the inclusion of these items was varied over the course of the study, they were excluded from this analysis. In addition to the patient completed assessment, a nurse reviewed the case notes to record height, indications for cholecystectomy, the presence of any other illnesses, and the surgical technique chosen. The indication for the operation and details of the frequency of biliary pain allowed each patient's case to be classified according to a four point ordinal acuity scale: emergency or urgent surgery (acute pancreatitis, cholangitis); acute cholecystitis or history of such (four or more periods of pain in the previous year); biliary pain less than four times in the previous year; asymptomatic (no biliary pain). At discharge the surgeon completed a checklist of possible postoperative complications. Each patient was followed up by post three months after their operation. The patients were sent a copy of the symptom questionnaire and the Nottingham health profile questionnaire with a stamped addressed envelope. Patients were also asked if they had been admitted to hospital (and if so why) or had visited their general practitioner or an accident and emergency department since their operation. The data were collated on a personal computer database and analysed using a standard statistical software package.

Observed differences in the presenting characteristics of patients undergoing open and laparoscopic surgery led us to define, without reference to any outcome data, a subset of patients within which the two groups would be comparable in terms of these presenting characteristics. This standard subset consisted of patients of 60 or under who had no other illnesses and had acute cholecystitis or history of such or had had biliary pain less than four times in the previous year.

The open and laparoscopic groups were compared on the basis of several outcome indicators: reduction in symptoms; improvements in general health status; occurrence of adverse events; and length of inpatient stay. These comparisons were then repeated within the standard subset only, and non-parametric statistics were used to assess the significance of the observed differences.

\section{Results}

The series included a total of 391 cholecystectomies, of which, 269 were of the open type and 111 used the laparoscopic technique. In a further 11 patients the laparoscopic procedure was converted to an open operation, and these patients were excluded from further analysis. Three patients who had had the open procedure were also excluded because they died within 30 days of the operation. A further two patients who had had the open procedure were excluded because they died of causes apparently unrelated to the cholecystectomy between 30 and 90 days after the operation. Of the remaining patients, $235(89 \%)$ who had the open procedure and $95(86 \%)$ who had laparoscopy had both baseline and follow up data.

The group given laparoscopic surgery (median age 63 , interquartile range 19.5 ) was younger than that given open surgery (median age 53, interquartile range $19, \mathrm{p}<0.001$, Mann-Whitney $U$ test) but did not differ significantly in terms of sex distribution $(76(32 \%)$ men in open surgery group $v$ $25(26 \%)$ in laparoscopic surgery group; $\mathrm{p}=0.3, \chi^{2}$ test) or mean body mass index (open surgery group 25.4 (standard deviation $4 \cdot 7) v$ laparoscopic surgery group $25 \cdot 4(3 \cdot 6)$ ). A higher proportion of patients undergoing open surgery presented with one or more other illnesses $(138 / 235(59 \%) v 47 / 95(50 \%)$ ), 
athough a $\chi^{2}$ test showed that this relation was not significant $(p=1 \cdot 2)$. The acuity coding of disease showed a significant association with technique ( $\mathrm{p}<0.05, \chi^{2}$ test) (table 1$)$.

STANDARD SUBSET

In the standard subset of patients 40 had open surgery and 35 laparoscopic surgery. The median age of those having open surgery was 44 (interquartile range 14) and that of those having laparoscopic surgery 45 (interquartile range 15); the proportions of male patients was similar (nine men $(23 \%)$ in open surgery group $v$ seven $(20 \%)$ in laparoscopic surgery group). The mean body mass indices remained close $(25.5$ (SD 3.7$)$ in open surgery group $v$ $24 \cdot 7(4 \cdot 0)$ in laparoscopic surgery group). Twenty eight $(70 \%)$ of the patients having open surgery were classified as having acute

Table 1 Classification of acuity of disease in patients given open and laparoscopic cholecystectomy. Values are numbers (percentages) of patients

\begin{tabular}{lcc}
\hline Acuity & $\begin{array}{c}\text { Open } \\
\text { surgery } \\
(n=227)^{\star}\end{array}$ & $\begin{array}{c}\text { Laparoscopic } \\
\text { surgery } \\
(n=86)^{\star}\end{array}$ \\
\hline $\begin{array}{l}\text { Emergency or urgent surgery } \\
\text { Acute or history of }\end{array}$ & $\begin{array}{c}44(19) \\
\text { acute cholecystitis }\end{array}$ & $5(6)$ \\
$\begin{array}{l}\text { Biliary pain } \\
\text { (<4 attacks in past year) }\end{array}$ & $63(28)$ & $24(28)$ \\
No biliary pain & $5(2)$ & 0 \\
\hline
\end{tabular}

^Eight patients given open surgery and nine given laparoscopic surgery were excluded because of incomplete information. cholecystitis or history of such compared with $24(69 \%)$ of those having laparoscopic surgery.

SYMPTOMS

Table 2 shows the preoperative prevalence of the six self reported symptoms. Within the standard subset no significant association was observed between any symptom and the surgical technique ( $p>0.05, \chi^{2}$ test). A similar lack of association between symptoms and technique was seen at the three month follow up.

The reduction in reported symptoms is shown in table 3, the alleviation of symptoms being expressed in terms of the proportion of sufferers who reported that the symptom was absent at follow up. For example, 32 of the $39(82 \%)$ patients who had laparoscopic surgery and reported pain preoperatively were relieved of this symptom three months after operation. The frequency with which patients who were free of a given symptom on admission reported that symptom at follow up is also shown in table 3 . Similar and significant symptom effects were seen in both groups within the standard subset, but neither group experienced consistently higher cure rates.

HEALTH STATUS

Table 4 shows the scores with the Nottingham health profile questionnaire on admission. Higher scores indicate poorer health. Within

Table 2 Prevalence of symptoms on admission among all patients and standard subset. Values are numbers (percentages) of patients

\begin{tabular}{lccccc}
\hline Symptom & \multicolumn{2}{c}{ All patients } & & \multicolumn{2}{c}{ Standard subset } \\
\cline { 2 - 5 } & $\begin{array}{c}\text { Open surgery } \\
(n=235)\end{array}$ & $\begin{array}{c}\text { Laparoscopic surgery } \\
(n=95)\end{array}$ & & $\begin{array}{c}\text { Open surgery } \\
(n=40)\end{array}$ & $\begin{array}{c}\text { Laparoscopic surgery } \\
(n=35)\end{array}$ \\
\hline Pain & $82(35)$ & $39(41)$ & $16(40)$ & $16(46)$ \\
Flatulence & $140(60)$ & $62(65)$ & $26(65)$ & $20(57)$ \\
Distended abdomen & $116(49)$ & $49(52)$ & $24(60)$ & $17(49)$ \\
Vomiting & $130(55)$ & $53(56)$ & $26(65)$ & $23(66)$ \\
Loss of appetite & $68(29)$ & $22(23)$ & $12(30)$ & $9(26)$ \\
Intolerance of fatty food & $158(67)$ & $73(77)$ & $31(78)$ & $27(77)$ \\
\hline
\end{tabular}

Table 3 Cure and occurrence of symptoms at follow up among all patients and standard subset. Values are proportions (percentages) of patients

\begin{tabular}{|c|c|c|c|c|c|c|c|c|}
\hline \multirow[t]{3}{*}{ Symptom } & \multicolumn{4}{|c|}{ All patients } & \multicolumn{4}{|c|}{ Standard subset } \\
\hline & \multicolumn{2}{|c|}{$\begin{array}{c}\text { Open surgery } \\
(n=235)\end{array}$} & \multicolumn{2}{|c|}{$\begin{array}{l}\text { Laparoscopic surgery } \\
\quad(n=95)\end{array}$} & \multicolumn{2}{|c|}{$\begin{array}{l}\text { Open surgery } \\
(n=40)\end{array}$} & \multicolumn{2}{|c|}{$\begin{array}{l}\text { Laparoscopic surgery } \\
(n=35)\end{array}$} \\
\hline & $\begin{array}{l}\text { Cure at } \\
\text { follow up }\end{array}$ & $\begin{array}{l}\text { Occurrence at } \\
\text { follow up }\end{array}$ & $\begin{array}{c}\text { Cure at } \\
\text { follow up }\end{array}$ & $\begin{array}{l}\text { Occurrence at } \\
\text { follow up }\end{array}$ & $\begin{array}{l}\text { Cure at } \\
\text { follow up }\end{array}$ & $\begin{array}{l}\text { Occurrence at } \\
\text { follow up }\end{array}$ & $\begin{array}{c}\text { Cure at } \\
\text { follow up }\end{array}$ & $\begin{array}{c}\text { Occurrence at } \\
\text { follow up }\end{array}$ \\
\hline $\begin{array}{l}\text { Pain } \\
\text { Flatulence } \\
\text { Distended abdomen } \\
\text { Vomiting } \\
\text { Loss of appetite } \\
\text { Intolerance of fatty food }\end{array}$ & $\begin{array}{c}62 / 82(76) \\
79 / 140(56) \\
63 / 116(54) \\
106 / 130(82) \\
44 / 68(64) \\
104 / 158(66)\end{array}$ & $\begin{array}{l}13 / 153(9) \\
19 / 95(20) \\
15 / 119(13) \\
7 / 105(7) \\
24 / 167(14) \\
16 / 77(21)\end{array}$ & $\begin{array}{l}32 / 39(82) \\
30 / 62(48) \\
34 / 49(69) \\
40 / 53(76) \\
14 / 22(64) \\
47 / 73(64)\end{array}$ & $\begin{array}{l}7 / 56(13) \\
8 / 33(24) \\
7 / 46(15) \\
1 / 42(2) \\
8 / 73(11) \\
3 / 22(14)\end{array}$ & $\begin{array}{l}14 / 16(88)^{\star} \\
14 / 26(54)^{\star} \\
12 / 24(50)^{\star} \\
22 / 26(85)^{\star} \\
9 / 12(75)^{\star} \\
22 / 31(71)^{\star}\end{array}$ & $\begin{array}{l}2 / 24(8) \\
2 / 14(14) \\
4 / 16(25) \\
1 / 14(7) \\
1 / 28(4) \\
0\end{array}$ & $\begin{array}{l}12 / 16(75)^{\star} \\
11 / 20(55)^{\star} \\
12 / 17(71)^{\star} \\
17 / 23(74)^{\star} \\
7 / 9(78) \\
16 / 27(59)^{\star}\end{array}$ & $\begin{array}{l}2 / 19(11) \\
5 / 15(33) \\
3 / 18(17) \\
1 / 12(8) \\
4 / 26(15) \\
1 / 8(13)\end{array}$ \\
\hline
\end{tabular}

${ }^{\star} \mathrm{p}<0.05$, McNemar's test of significance of change.

Table 4 Scores on admission with Nottingham health profile questionnaire among all patients and standard subset. Values are means (medians, interquartile ranges)

\begin{tabular}{|c|c|c|c|c|}
\hline \multirow[t]{2}{*}{ Dimension } & \multicolumn{2}{|c|}{ All patients } & \multicolumn{2}{|c|}{ Standard subset } \\
\hline & $\begin{array}{l}\text { Open surgery } \\
(n=235)\end{array}$ & $\begin{array}{c}\text { Laparoscopic surgery } \\
(n=95)\end{array}$ & $\begin{array}{c}\text { Open surgery } \\
(n=40)\end{array}$ & $\begin{array}{c}\text { Laparoscopic surgery } \\
(n=35)\end{array}$ \\
\hline $\begin{array}{l}\text { Energy } \\
\text { Pain } \\
\text { Emotional reactions } \\
\text { Sleep } \\
\text { Social isolation } \\
\text { Mobility }\end{array}$ & $\begin{array}{c}37 \cdot 1(24 \cdot 0,63 \cdot 2) \\
26 \cdot 3(19 \cdot 7,43 \cdot 1) \\
17 \cdot 5(9 \cdot 8,27 \cdot 4) \\
28 \cdot 4(12 \cdot 6,50 \cdot 5) \\
8 \cdot 3(0 \cdot 0,0 \cdot 0) \\
13 \cdot 9(0 \cdot 0,21 \cdot 8)\end{array}$ & $\begin{array}{c}28 \cdot 4(0 \cdot 0,63 \cdot 2) \\
21 \cdot 1(12 \cdot 9,36 \cdot 8) \\
16 \cdot 4(0 \cdot 0,23 \cdot 7) \\
28 \cdot 9(12 \cdot 6,56 \cdot 6) \\
5 \cdot 1(0 \cdot 0,0 \cdot 0) \\
7 \cdot 8(0 \cdot 0,10 \cdot 6)\end{array}$ & $\begin{array}{c}32 \cdot 3(0 \cdot 0,62 \cdot 6) \\
22 \cdot 3(6 \cdot 4,42 \cdot 8) \\
14 \cdot 8(10 \cdot 1,20 \cdot 9) \\
22 \cdot 6(12 \cdot 6,34 \cdot 8) \\
2 \cdot 2(0 \cdot 0,0 \cdot 0) \\
5 \cdot 9(0 \cdot 0,7 \cdot 9)\end{array}$ & $\begin{array}{c}24 \cdot 2(0 \cdot 0,39 \cdot 2) \\
15 \cdot 8(0 \cdot 0,23 \cdot 4) \\
18 \cdot 4(0 \cdot 0,36 \cdot 8) \\
23 \cdot 5(12 \cdot 6,50 \cdot 4) \\
6 \cdot 5(0 \cdot 0,0 \cdot 0) \\
3 \cdot 4(0 \cdot 0,0 \cdot 0)\end{array}$ \\
\hline
\end{tabular}


Table 5 Scores after three months with Nottingham health profile questionnaire among all patients and standard subset. Values are means (medians, interquartile ranges)

\begin{tabular}{lccccc}
\hline Dimension & \multicolumn{2}{c}{ All patients } & & \multicolumn{2}{c}{ Standard subset } \\
\cline { 2 - 5 } \cline { 5 - 6 } & $\begin{array}{c}\text { Open surgery } \\
(n=235)\end{array}$ & $\begin{array}{c}\text { Laparoscopic surgery } \\
(n=95)\end{array}$ & & $\begin{array}{c}\text { Open surgery } \\
(n=40)\end{array}$ & $\begin{array}{c}\text { Laparoscopic surgery } \\
(n=35)\end{array}$ \\
\hline Energy & $20 \cdot 2(0 \cdot 0,27 \cdot 8)$ & $20 \cdot 1(0 \cdot 0,24 \cdot 0)$ & & $12 \cdot 5(0 \cdot 0,24 \cdot 0)^{\star}$ & $11 \cdot 4(0 \cdot 0,24 \cdot 0)^{\star}$ \\
Pain & $8 \cdot 5(0 \cdot 0,10 \cdot 0)$ & $5 \cdot 5(0 \cdot 0,0 \cdot 0)$ & & $7 \cdot 1(0 \cdot 0,0 \cdot 0)^{\star}$ & $3 \cdot 6(0 \cdot 0,0 \cdot 0)^{\star}$ \\
Emotional reactions & $7 \cdot 8(0 \cdot 0,9 \cdot 8)$ & $8 \cdot 8(0 \cdot 0,9 \cdot 8)$ & & $3 \cdot 9(0 \cdot 0,0 \cdot 0)^{\star}$ & $4 \cdot 0(0 \cdot 0,0 \cdot 0)^{\star}$ \\
Sleep & $17 \cdot 2(0 \cdot 0,34 \cdot 3)$ & $20 \cdot 9(0 \cdot 0,34 \cdot 3)$ & & $12 \cdot 2(0 \cdot 0,12 \cdot 6)^{\star}$ & $16 \cdot 0(0 \cdot 0,16 \cdot 1)^{\star}$ \\
Social isolation & $5 \cdot 8(0 \cdot 0,0 \cdot 0)$ & $3 \cdot 2(0 \cdot 0,0 \cdot 0)$ & & $0 \cdot 5(0 \cdot 0,0 \cdot 0)$ & $3 \cdot 3(0 \cdot 0,0 \cdot 0)$ \\
Mobility & $10 \cdot 2(0 \cdot 0,11 \cdot 2)$ & $5 \cdot 0(0 \cdot 0,0 \cdot 0)$ & & $4 \cdot 4(0 \cdot 0,0 \cdot 0)$ & $2 \cdot 1(0 \cdot 0,0 \cdot 0)$ \\
\hline
\end{tabular}

${ }^{\star} \mathrm{p}<0.05$ relative to corresponding admission score, Wilcoxon's matched pairs signed ranks test.

the standard subset none of the six dimensions showed a significant difference when the two groups were compared ( $p>0.05$, MannWhitney $U$ test). Table 5 gives the corresponding scores at three month follow up. Again, no significant differences were seen between the two groups within the standard subset. Significant improvements, between admission and follow up, were seen in the same four of the six dimensions $(p<0.05$, Wilcoxon's matched pairs signed ranks test) for each of the standard groups.

\section{ADVERSE EVENTS}

One or more postoperative complications was reported in $45(19 \%)$ open procedures and in six $(6 \%)$ laparoscopic procedures. Within the standard subset complications were reported in five $(13 \%)$ open procedures and one (3\%) laparoscopic procedures $(p=0 \cdot 2$, Fisher's exact test).

Table 6 gives the incidence at follow up, as reported by the patients, of three potentially adverse events. Within the standard subset only readmission was significantly associated with technique ( $p=0.02$, Fisher's exact test). However, of the five patients who had laparoscopic surgery who were readmitted, only two of the admissions were associated with reasons that might have represented complications of the cholecystectomy: investigation for bowel problems and biliary leak, pancreatitis, peritonitis.

When the readmission indicator was modified on this basis the incidence was reduced to $5 \cdot 7 \%$ (two patients), which was not significant in comparison with the open subset.

\section{LENGTH OF STAY}

The laparoscopic procedure was associated with a substantially reduced mean length of stay (mean 4.5 days, median 4 , interquartile range $2 v 9 \cdot 8$, median 8 , interquartile range 5). This relation held within the standard subset (mean $4 \cdot 1$, median 4 , interquartile range $2 v$ mean 8.3 , median 7 , interquartile range 2 ; $\mathrm{p}<0.05$, Mann-Whitney U test).

\section{Discussion}

As we have said, the introduction of laparoscopic cholecystectomy in the United Kingdom and other countries has not been supported by the publication of randomised controlled comparisons with the surgical technique it has now almost replaced. It has been suggested that, given the apparent benefits, in terms of avoiding many of the disadvantages of a major abdominal operation, and the new technique's consequent rapid uptake, establishing such trials would be impractical. ${ }^{3}$ This situation is by no means unique to biliary tract surgery, and there are a range of reasons, including both the practical and ethical, why surgery in general has not been well served by the randomised controlled trial. ${ }^{9}$ In recent years, the growth of outcomes research, most notably in the form of the Patient Outcome Research Team (PORT) programme in the United States, ${ }^{10}$ has promoted the use of observational studies as a practical alternative for gathering information on effectiveness. Critics of this approach remind us of its limitations due to the potential for allocation bias, ${ }^{11} 12$ but when a randomised controlled trial is no longer, or never was, a realistic option, the value and limitations of other methods should be understood and accepted. Science has many methods for finding things out, and in many respects a randomised controlled trial is the theoretical ideal. However, a science that insists, in the face of formidable practical constraints, on the ideal or nothing will remain unnecessarily uninformed.

The limitations of observational experiments in assessing relative effectiveness are apparent in our study - the two groups of patients were clearly different. The sample having laparoscopic surgery was younger, perhaps had fewer other illnesses, and was underrepresented in our emergency and acute cholecystitis categories. Given that the laparoscopic series represents the initial experience of the new procedure within the study unit, such differences are unsurprising, and the results describe the types of patients

Table 6 Incidence of adverse events.reported by patients. Values are numbers (percentages) of patients

\begin{tabular}{lccccc}
\hline Adverse event & \multicolumn{3}{c}{ All patients } & & \multicolumn{2}{c}{ Standard subset } \\
\cline { 2 - 3 } \cline { 5 - 6 } & $\begin{array}{c}\text { Open surgery } \\
(n=235)\end{array}$ & $\begin{array}{c}\text { Laparoscopic surgery } \\
(n=95)\end{array}$ & & $\begin{array}{c}\text { Open surgery } \\
(n=40)\end{array}$ & $\begin{array}{c}\text { Laparoscopic surgery } \\
(n=35)\end{array}$ \\
\hline $\begin{array}{l}\text { Visited accident and emergency } \\
\text { department }\end{array}$ & $18(8)$ & $5(5)$ & $1(3)$ & $2(6)$ \\
$\begin{array}{l}\text { Visited general practitioner } \\
\text { Admitted to hospital }\end{array}$ & $\begin{array}{l}45(19) \\
15(6)\end{array}$ & $10(11)$ & $10(25)$ & $4(11)$ \\
\hline
\end{tabular}


presenting when the technique was introduced. The selection of a large and comparable subset of patients found within the two samples is a simple and practical device which aids the interpretation of the outcomes observed within the whole series. Although undetected differences between the two groups may remain, the similarity of preoperative symptom scores and scores in the Nottingham health profile questionnaire in the standard subsets of the two groups suggests that selection on the basis of age, acuity, and coexistent illnesses achieved samples that should have comparable outcomes.

Our data show that substantial reductions in symptoms and improvements in general health status are obtained at three months. Importantly, this result holds irrespective of the surgical technique used. Although mortality at three months was marginally higher than had been anticipated, review of the individual cases indicated that the deaths tended to be associated with malignant disease or the presence of many other illnesses. No deaths were seen in the group given laparoscopic surgery. Fewer postoperative complications were seen in this group. As expected, length of stay was greatly reduced in the case of the laparoscopic procedure. Whereas this reduction in complications - as recorded by the surgeon at discharge - might itself be due to the shorter length of stay, no significant differences were obtained between the groups in terms of rates of attendance at general practitioners' surgeries or accident and emergency departments or of readmission - as reported by the patient - for the three months after admission. Although the patient reports gave only limited information on the reasons for readmission, they were sufficient to identify a subset relevant to the cholecystectomy. We emphasise that the study design cannot address complications of cholecystectomy that may develop beyond three months.

These results suggest that the benefits of the laparoscopic technique, in terms of the much shorter length of stay and the reduced incidence of complications, are associated with a broadly defined three month outcome that is as good as that obtained with the open operation. If the financial costs of laparoscopic cholecystectomy are lower than those of the the open procedure, then we have evidence that these savings are not being made at the expense of the patient. Similarly, if there are benefits to patients in terms of shorter and easier convalescence or return to work, or both, then these are not offset by a poorer quality outcome. In part, these conclusions are based on a subset of patients with fairly uncomplicated disease and we cannot apply these results to patients with more complex disease, who are poorly represented among those given laparoscopic surgery. Initially, acute cholecystitis was seen as contraindication for laparoscopic surgery. ${ }^{13}$ Although there will always be a few patients for whom the technique is inappropriate, the laparoscopic procedure is now used routinely in the treatment of acute inflammation. ${ }^{14}$ As such trends continue, observational studies using historical controls can continue to contribute to the evaluation of the new technique.

1 Dubois F, Icard P, Berthelot G, Levard H. Coelioscopic cholecystectomy. Ann Surg 1990;211:60-2

Reddick EJ, Olsen DO. Laparoscopic laser cholecystectomy. Surg Endosc 1989;3:131-3.

3 Wolfe BM, Gardiner B, Frey CF. Laparoscopic cholecystectomy - a remarkable development. f $A M A$ 1991;265:1573-4

4 Zucker KA, Bailey RW, Gadacz TR, Imbembo AL. Laparoscopic guided cholecystectomy. Am f Surg 1991; 161:36-44.

5 CASPE Research. The CASPE/Freeman outcomes study. Final report. London: CASPE Research, 1991.

6 Bardsley MJ, Coles JM. Practical experience in auditing patient outcomes. Quality in Health Care 1992;1:124-30.

7 Hunt SM, McEwen J, McKenna SP. Measuring health status. Beckenham: Croom Helm, 1986.

8 Bardsley MJ, Venables CW, Watson J, Goodfellow J, Wright PD. Evidence for validity of a health status measure in assessing short term outcomes of cholecystectomy. Quality in Health Care 1992;1:10-4.

9 Pollock AV. The rise and fall of the random controlled trial in surgery. Theoretical Surgery 1989;4:163-70.

10 Goldberg HI, Cummings MA. Conducting medical effectiveness research: a report from the Inter-PORT effectiveness research: a report from the
Work Groups. Medical Care 1994;32:JS1-2.

11 Sheldon TA. Please bypass the PORT. BMF 1994;309: $142-3$.

12 MacRae K. Validity of assessing change through audit. $B M f$ 1994;309:18-9.

13 Sackier JM, Berci G. Diagnostic and interventional laparoscopy for the general surgeon. Contemporary Surgery $1990 ; 37(4): 15-26$.

14 Flowers JL, Bailey RW, Scovil WA, Zucker KA. The Baltimore experience with laparoscopic management of acute cholecystitis. Am $\mathcal{F}$ Surg 1991;161:388-92. 